\title{
Implementasi Teknik Watermarking Menggunakan Metode Discrete Wavelet Transform (DWT) dan Singular Value Decomposition (SVD) pada Citra Digital
}

\author{
Verryna Adzillatul Fathiha \\ Universitas Negeri Surabaya \\ verrynafathiha@mhs.unesa.ac.id
}

\begin{abstract}
ABSTRAK. Watermarking merupakan teknik penyembunyian data/informasi kedalam suatu citra digital yang tidak kasat mata atau tidak dapat diketahui secara visual. Penyembunyian data/informasi kedalam citra tersebut bersifat rahasia. Karena tahan terhadap proses digitalisasi, teknik watermarking dapat digunakan untuk melindungi kepemilikan suatu citra digital. Ada tiga kriteria yang harus diperhatikan dalam watermarking pada citra digital, diantaranya adalah security, impreceptibily, dan robustness. Pada tugas Penulisan Karya Ilmiah (PI) ini dibuat suatu program watermarking menggunakan metode Discrete Wavelet Transform (DWT) dan Singular Value Decomposition (SVD) yang kemudian juga akan dipaparkan bagaimana cara menggunakan program watermarking yang telah dibuat. Keunggulan dari program ini citra yang digunakan dalam program watermarking ini dapat berupa citra berwarna maupun citra grayscale. Program watermarking ini dibuat menggunakan bahasa pemrograman $\mathrm{C}++$ melalui aplikasi Matlab

Kata Kunci : Wateramarking, Singular Value Decomposition (SVD), Discrete Wavelet Transform (DWT), Matlab, Bahasa Pemrograman C++.
\end{abstract}

ABTRACT. Watermarking is a technique of hiding data / information into a digital image that cannot be known visually. Hiding data / information into the image is confidential. Because it is resistant to the digitization process, watermarking techniques can be used to protect the ownership of a digital image. There are three criteria that must be considered in watermarking digital images, including security, imperceptibility, and robustness. In this Scientific Paper Writing (PI) task, a watermarking program was created using the Discrete Wavelet Transform (DWT) and Singular Value Decomposition (SVD) methods which will then explain how to use the watermarking program that has been made. The advantage of this program is that the images used in this watermarking program can be in the form of color images or grayscale images. This watermarking program was created using the $C++$ programming language through the Matlab application

Keywords: Wateramarking, Singular Value Decomposition (SVD), Discrete Wavelet Transform (DWT), Matlab, C++ Programming.

\section{PENDAHULUAN}

Perkembangan ilmu teknologi yang sangat pesat terutama dibidang informasi memiliki manfaat yang sangat besar bagi masyarakat. Semua data-data multimedia seperti citra, video maupun audio yang disajikan dalam bentuk digital telah mudah diakses atau didapatkan melalui internet. Perlu diketahui bahwa perkembangan ilmu teknologi dibidang informasi ini tidak hanya memberikan dampak positif saja, kemudahan dalam mengakses, meyimpan ataupun menggandakan suatu data multimedia (citra, video atau audio) yang diperoleh dari internet dapat menyebabkan terjadinya pelanggaran-pelanggaran terhadap suatu hak kepemilikan dari suatu data multimedia tersebut. Sehingga, terkadang keaslian dari data multimedia (citra, video atau audio) tersebut tidak lagi terjaga dikarenakan setiap orang dapat mengolah kembali dan mengubah informasi-informasi yang ada dalam suatu citra, video atau audio digital tersebut dengan mudah dan membagikannya atau mengunggahnya kembali di internet. Untuk itu perlu adanya perlindungan hak kepemilikan dalam dunia informasi agar meminimalisir terjadinya plagiasi.

Citra digital merupakan suatu data multimedia yang paling sering digunakan. Oleh karna itu terjadinya plagiasi terhadap suatu citra digital sangat sering sekali ditemukan. Untuk menjaga hak kepemilikan dari suatu citra digital dibutuhkan metode pemberian tanda didalam citra digital. Proses pengamanan terhadap suatu citra digital disebut dengan image security [1]. Salah satu metode pengamanan tersebut yaitu watermarking. Watermarking merupakan suatu teknik penyembunyian data/informasi rahasia kedalam citra digital baik berupa logo, teks ataupun citra lain yang menginformasikan sang pemilik citra digital tanpa merusak citra digital asli sehingga tetap terlihat seperti citra digital aslinya. Teknik penyembunyian data/informasi ini bersifat rahasia. Orang lain tidak akan menyadari bahwa didalam citra digital tersebut tertanam suatu data/informasi dari pemilik citra digital. 
Watermarking terdiri dari dua proses yaitu proses embedding dan proses Ekstraction Embedding. Pada proses embedding disini dilakukan suatu proses penyisipan informasi dari sang pemilik citra. Kemudian pada proses ekstraction embedding dilakukan suatu proses pengambilan informasi yang ada didalam citra digital yang telah terwatermark [2]

Singular Value Decomposition (SVD) merupakan salah satu teknik dalam aljabar linear yang memiliki banyak sekali fungsi dalam pengolahan suatu citra digital dan bidang pemrosesan sinyal. SVD juga merupakan suatu teknik yang handal dalam melakukan analisis dan komputasi matriks dengan cara mengekspos struktur geometrinya sehingga bisa dilihat beberapa properti penting dari matriks tersebut. Dalam proses pembuatan watermarking ini diperlukannya metode SVD karena SVD memiliki beberapa sifat unggul yang dapat membantu proses watermarking yaitu nilai-nilai singular dari suatu citra memiliki stabilitas yang baik dan nilai-nilai singular mewakili sifat intrinsik citra [3]. Adapun tujuan utama dari SVD yaitu mendekomposisi sebuah matrik rectangular kedalam dua matrik orthogonal dan satu matrik diagonal. Discrete Wavelet Transform (DWT) merupakan teknik yang dapat menghasilkan koefisien keluaran dari highpass dan lowpass filter. Dengan menggunakan koefisien DWT tersebut citra asli dapat direkontruksi. Proses dari rekontruksi tersebut disebut dengan Inverse Discrete Wavelet Transform (IDWT). Dalam pembuatan program watermarking kali ini akan digunakana metode Discrete Wavelet Transform (DWT) dan Singular Value Decomposition (SVD) yang akan menghasilkan suatu citra terwatermark yang tahan terhadap serangan atau proses-proses digitalisasi seperti noising, blurring, cropping dan lain-lain).

\section{METODE PENELITIAN}

A. Penyisipan Watermark

Dalam program watermarking ini, akan disisipkan suatu citra yang digunakan sebagai citra watermark kedalam suatu citra asli agar citra asli tersebut terlindungi hak ciptanya. Berikut merupakan tahapan drai penyisipan citra watermark tersebut.

1. Memilih citra asli yang akan disisipi oleh citra watermark.

2. Memilih citra watermark.

3. Digitalisasi citra agar citra terbaca oleh computer/laptop.

4. Menganalisis citra menggunakan Singlar Value Decomposition (SVD) sebagai metode Watermark.

B. Alur Penyisipan Watermark dan Ekstraksi

Watermark hasil

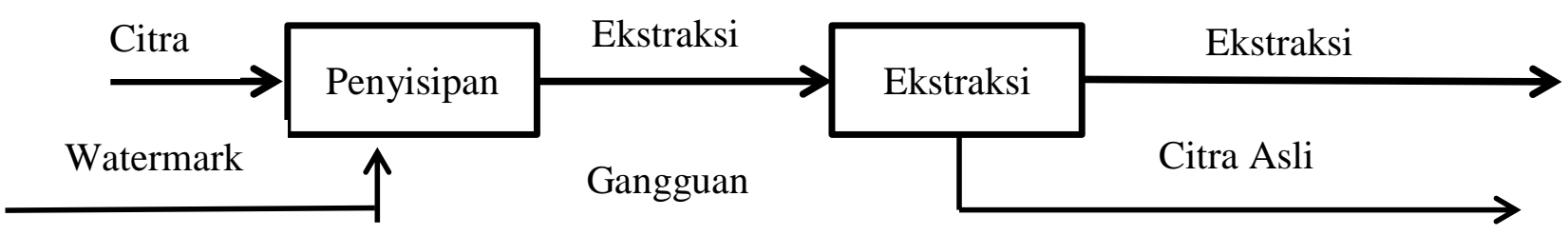

C. Flowchart Aplikasi Watermarking

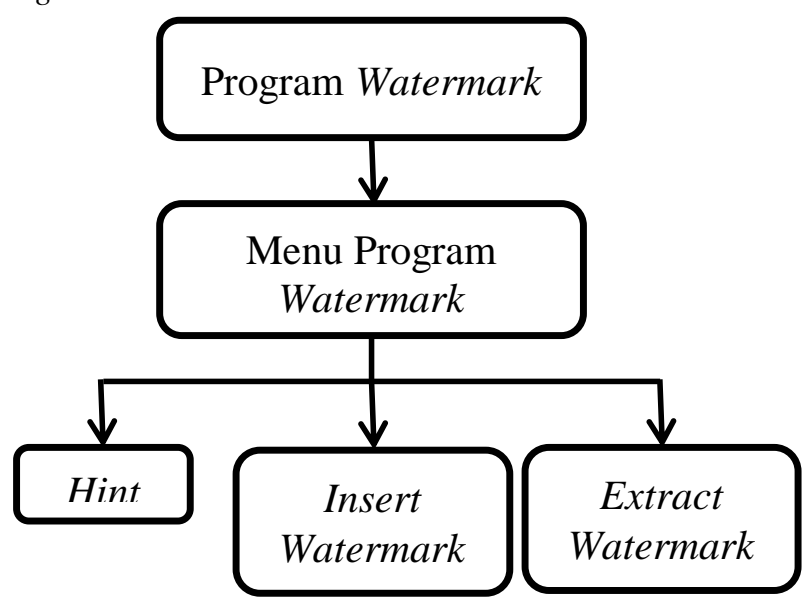


D. Desain Program

Langkah pertama dalam membuat program watermarking ialah memulai membuka program Matlab

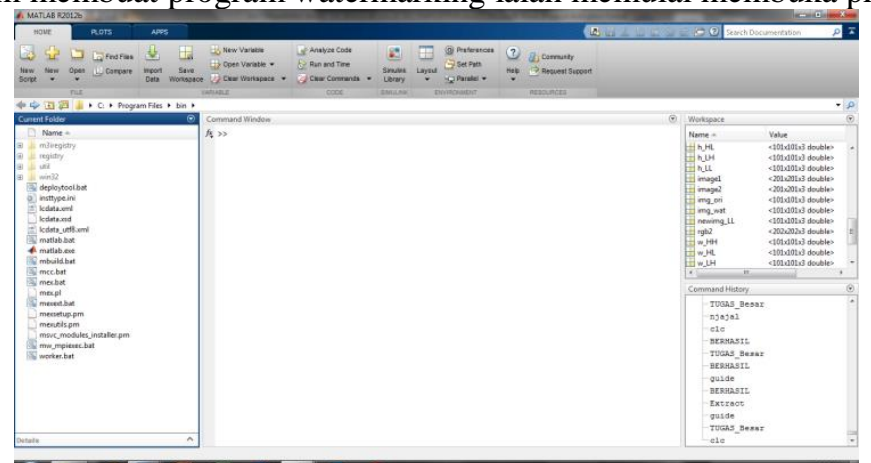

Gate
Gambar 1. Tampilan Matlab

Setelah terbuka, pada command window diketik "guide" untuk membuat gui program watermarking.

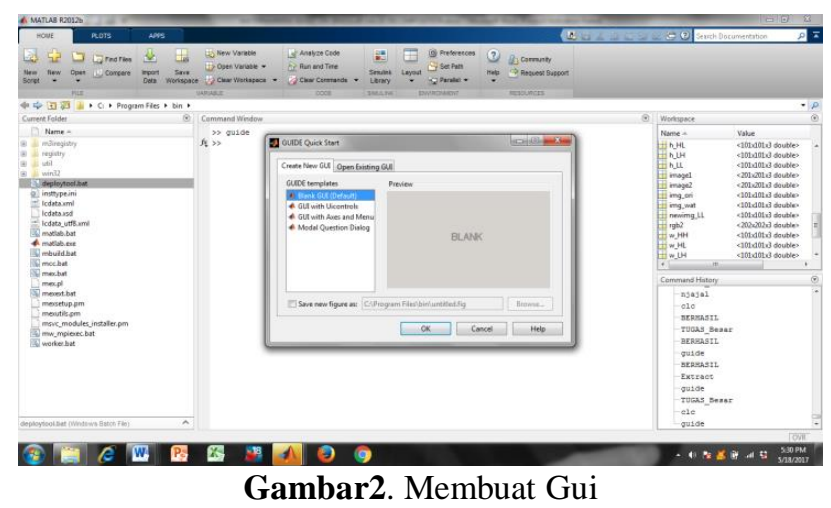

Membuat tampilan program watermarking.

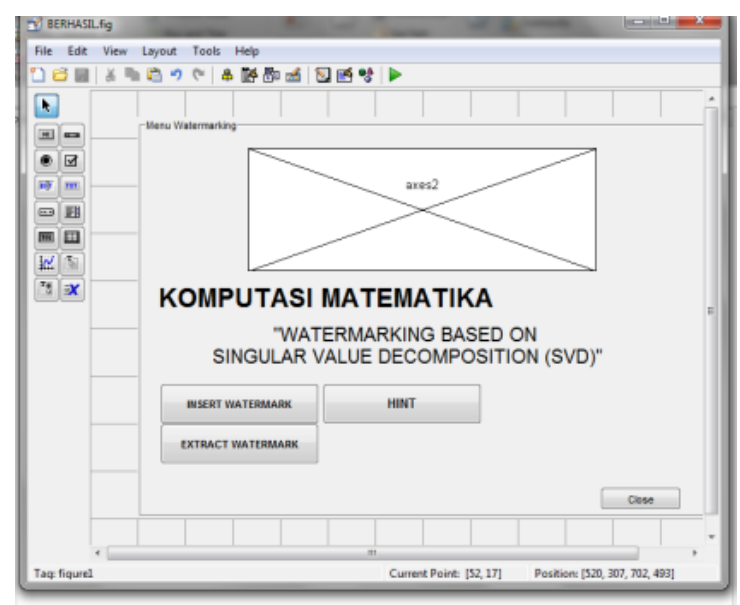

Gambar 3. Tampilan Gui Awal 


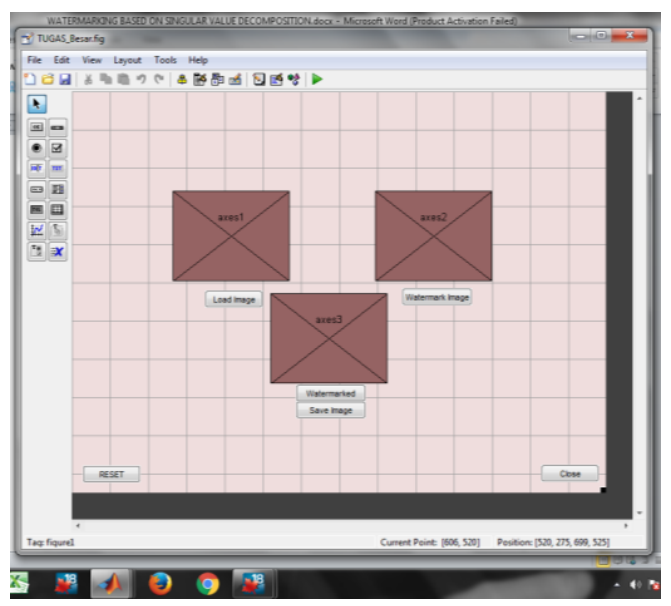

Gambar 4. Tampilan Gui Kedua

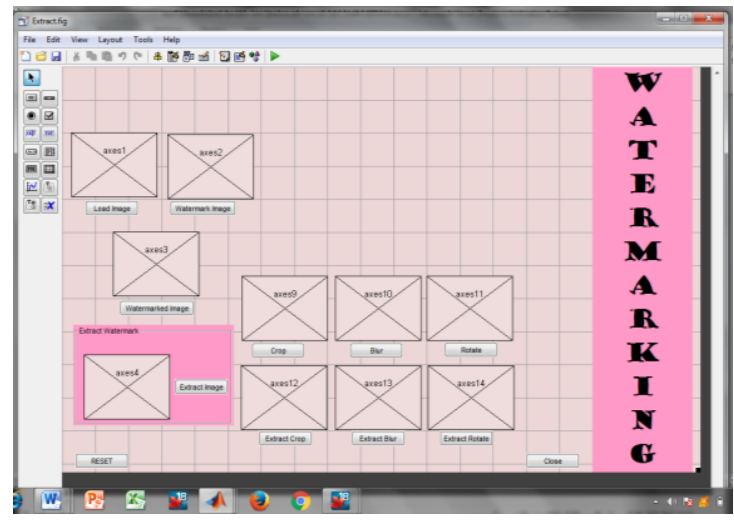

Gambar 5. Tampilan Gui Ketiga

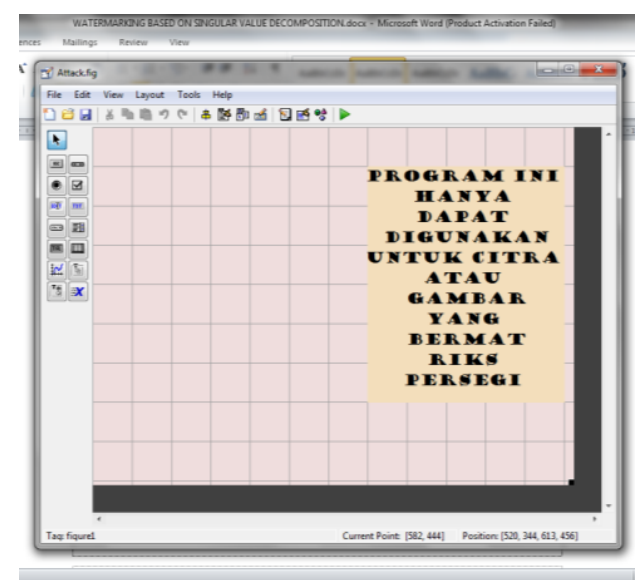

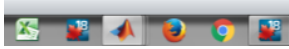

Gambar 6. Tampilan Gui Keempat

\section{HASIL DAN PEMBAHASAN}

A. Tampilan Menu Program

Pada program ini user akan diberikan tampilan menu utama beserta pilihan yang dapat dipilih oleh user. 
B. Tampilan Menu Hint

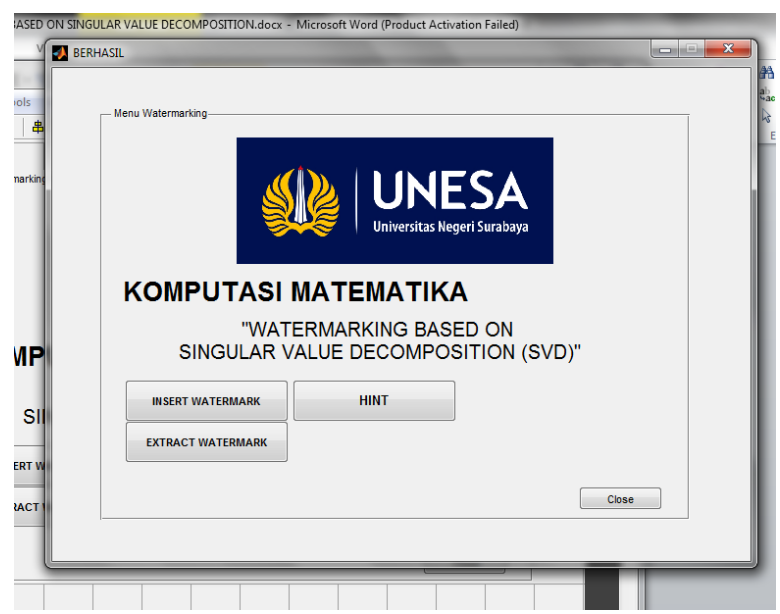

Gambar 7. Hasil Tampilan Awal

Saat user memilih menu "Hint" akan muncul tampilan sebagai berikut.

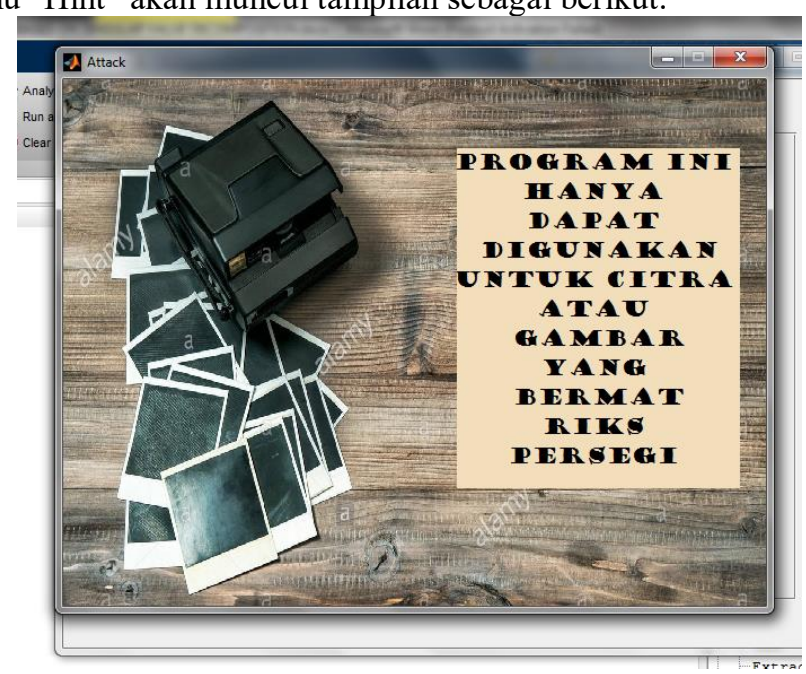

Gambar 8. Hasil Tampilan Menu Hint

Pada pilihan "Hint" user akan diberikan pemberitahuan bahwa program hanya dapat dijalankan dengan menginputkan gambar yang bermatriks persegi. 
C. Tampilan Menu Insert Watermark

Saat user memilih menu "Insert Watermark" akan muncul tampilan sebagai berikut.

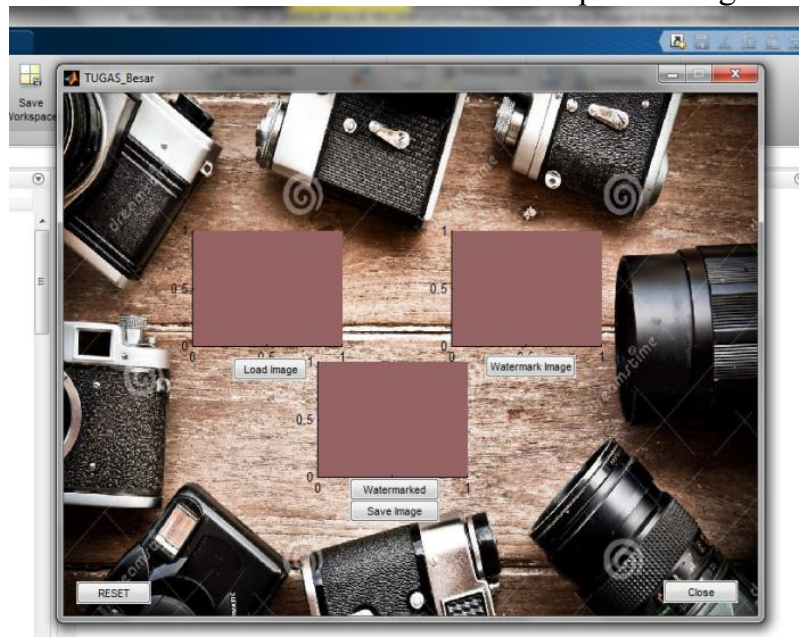

Gambar 9. Tampilan Menu Insert Watermark

Pada menu "Insert Watermark", pada menu ini user dapat mewatermark image yang diinginkan dengan menginputkan gambar yang akan di watermark, dan menginputkan gambar yang akan dijadikan watermark. Setelah menginputkan gambar, langkah selanjutnya user menekan tombol "Watermark" maka program akan menghasilkan gambar yang telah terwatermark.

D. Tampilan Menu Extract Watermark

Saat user memilih menu "Extract Watermark" akan muncul tampilan sebagai berikut.

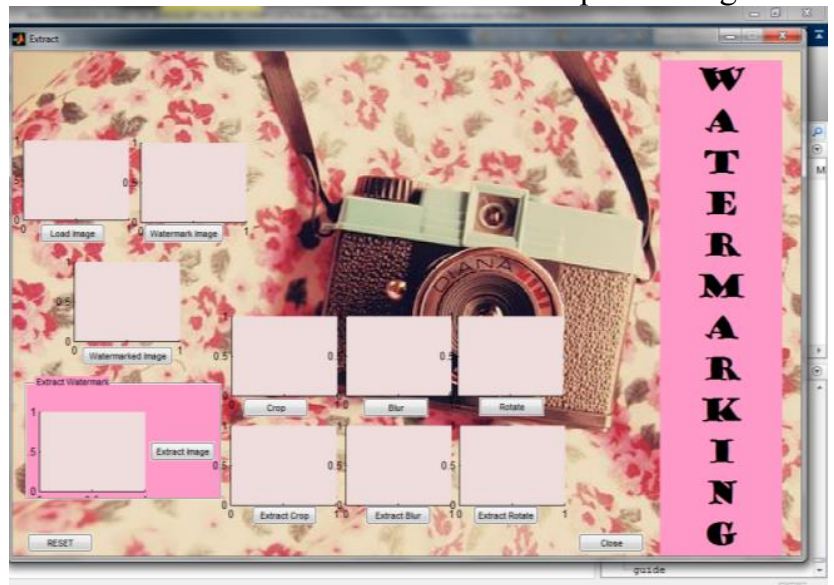

Gambar 10. Tampilan Menu Extract Watermark

Pada menu "Watermarking", citra yang telah terwatermark dapat dapat di crop, di blur, dan rotate sesuai keinginan user. 


\section{E. Pembahasan}

Pada penelitian kami membuat sebuah program watermark dengan menggunakan software Matlab. Hasil penelitian dari program kami yaitu berupa program "Implementasi Tenknik Watermarking Menggunakan Metode Discrete Wavelet Transform (DWT) dan Singular Value Decomposition (SVD) pada Citra Digital”. Program ini merupakan suatu program yang dibuat untuk membantu para pemilik suatu karya cipta yang berupa citra digital dalam melindungi hasil karyanya agar tidak diakui oleh orang lain. Dalam program ini, citra asli akan disisipkan identitas dari sang pemilik citra tanpa mengubah bentuk atau warna dari citra asli tersebut. Dangan demikian hanya sang pemilik citralah yang dapat mengetahui citra tersebut adalah miliknya atau bukan. Program "Implementasi Tenknik Watermarking Menggunakan Metode Discrete Wavelet Transform (DWT) dan Singular Value Decomposition (SVD) pada Citra Digital" ini dibuat dengan bahasa pemrograman $\mathrm{C}++$ melalui aplikasi Matlab. Metode yang digunakan pada Program watermarking ini yaitu metode Discrete Wavelet Transform (DWT) dan Singular Value Decomposition (SVD). Dipilihnya SVD sebagai metode dalam pembuatan program ini dikarenakan dalam sudut pandang pengolahan citra, singular value dari suatu citra memiliki stabilitas yang baik, dimana ketika ada sedikit gangguan yang diberikan pada citra tersebut, singular value tidak berubah secara signifikan. Kemudian kuntungan lainnya adalah ukuran matriks dari transformasi metode SVD tidak tetap dan dapat berupa persegi atau lingkaran. Kemudian singular value mengandung informasi properti persamaan linear citra/gambar. Kemudian juga digunakannya metode Discrete Wavelet Transform (DWT) karena Discrete Wavelet Transform (DWT) merupakan teknik yang dapat menghasilkan koefisien keluaran dari highpass dan lowpass filter. Dengan menggunakan koefisien DWT tersebut citra asli dapat direkontruksi. Proses dari rekontruksi tersebut disebut dengan Inverse Discrete Wavelet Transform (IDWT)

Algoritma yang digunakan dalam program ini adalah algoritma yang diusulkan Ruizhen Liu dan Tieniu Tan. Yaitu dengan menjumlahkan secara langsung antara citra watermark pada intensitas tertentu dengan matriks diagonal hasil dekomposisi SVD dari citra pembawa. Berikut merupakan hasil dari program watermarking yang telah kami buat.

- Citra Asli

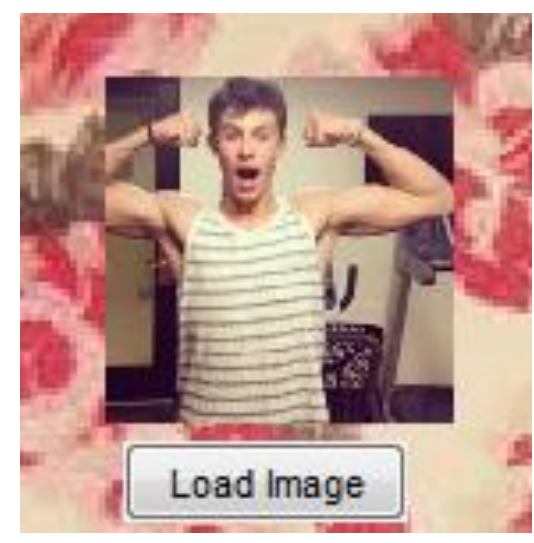

Gambar 11. Tampilan citra asli 
- Citra Watermark

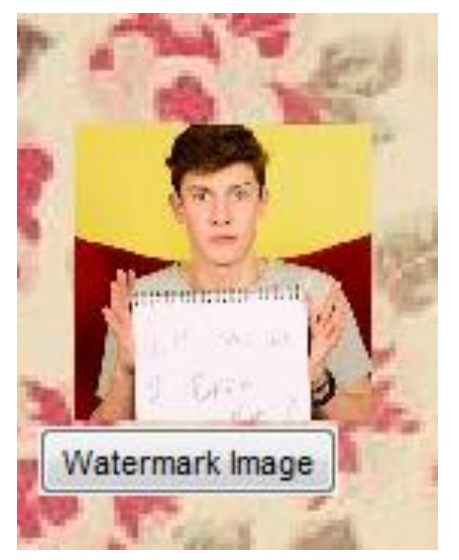

Gambar 12. Tampilan citra watermark

- Citra Terwatermark

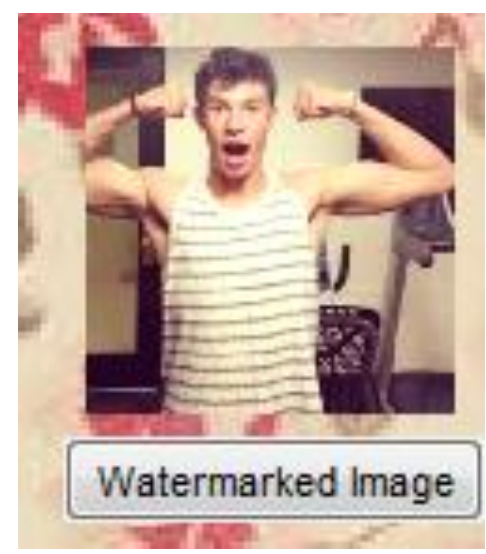

Gambar 13. Tampilan citra terwatermark

- Citra Ekstrak

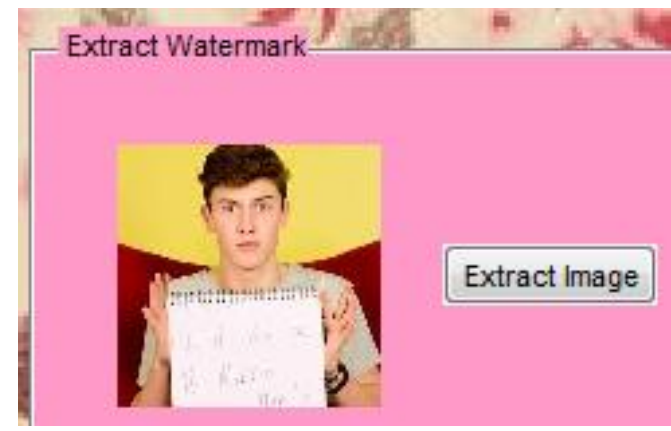

Gambar 14. Tampilan citra ekstrak

- Ketika citra terwatermark di crop, blur dan rotasi maka citra terwatermark yang diesktrak akan berupa sebagai berikut. 


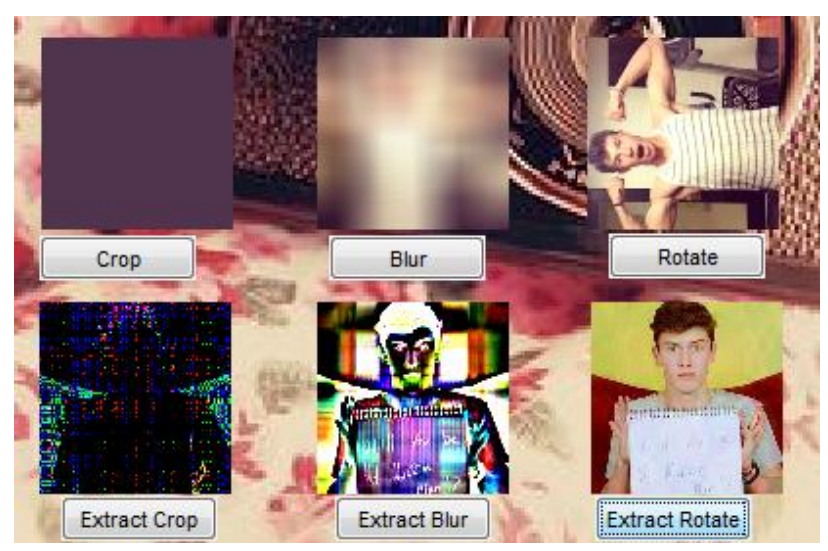

Gambar 14. Tampilan citra ekstrak yang diberi gangguan

Citra yang ter-watermark, ketika diberi gangguan seperti crop, blur dan rotasi akan tidak akan mempengaruhi atau menghilangkan identitas atau data/informasi yang telah disisipkan ke dalam citra asli.

\section{KESIMPULAN DAN SARAN}

A. Kesimpulan

Watermarking merupakan cara untuk menyisipkan watermark atau proses penambahan kode secara permanen ke dalam citra digital yang ingin dilindungi hak ciptanya dengan tidak merusak citra aslinya dan tahan terhadap serangan. Program watermark ini merupakan suatu program yang dibuat untuk membantu para pemilik suatu karya cipta yang berupa citra digital dalam melindungi hasil karyanya agar tidak diakui oleh orang lain. Program ini menggunakan metode Discrete Wavelet Transform (DWT) dan SVD (Singular Value Decomposition) dengan menggunakan software Matlab. Pada program ini citra digital yang digunakan dapat berupa citra berwarna ataupun citra grayscale. Dalam program ini juga diberikan gangguan-gangguan seperti crop, blur, dan rotate citra yang telah terwatermark. Kemudain terdapat button ekstraksi pada gambar yang telah di crop, blur dan rotate.

Setelah dilakukan percobaan dalam program watermarking ini diperoleh hasil bahwa ketika citra terwatermark diberi gangguan seperti crop, blur dan rotate, tidak akan mempengaruhi atau menghilangkan identitas atau data/informasi yang telah disisipkan ke dalam citra asli. Sehingga program watermarking yang dibuat dengan menggunakan metode Discrete Wavelet Tranform (DWT) dan Singular Value Decomposition (SVD) ini memiliki ketahanan yang cukup kuat dari gangguan-gangguan yang dibuat.

B. Saran

Diharapkan masyarakat Indonesia lebih memiliki rasa ingin tahu untuk mempelajari programprogram, seperti Matlab yang sangat bermanfaat untuk kemajuan bangsa Indonesia dalam hal Teknologi. Selain itu, program-program tersebut juga memudahkan masyarakat untuk melakukan aktivitas sehari-hari. 


\section{DAFTAR PUSTAKA}

[1] K. Kurniawan, I. A. Siradjuddin, and A. Muntasa, "Keamanan Citra Dengan Watermarking Menggunakan Pengembangan Algoritma Least Significant Bit," J. Inform., vol. 13, no. 1, pp. 9-14, 2016.

[2] P. Jain and U. Ghanekar, "Robust watermarking technique for textured images," Procedia Comput. Sci., vol. 125, no. 2009, pp. 179-186, 2018.

[3] R. S. Run, S. J. Horng, J. L. Lai, T. W. Kao, and R. J. Chen, “An improved SVD-based watermarking technique for copyright protection," Expert Syst. Appl., vol. 39, no. 1, pp. 673-689, 2012.

[4] S. L. Jia, “A novel blind color images watermarking based on SVD," Optik (Stuttg)., vol. 125, no. 12, pp. 2868-2874, 2014.

[5] M. Sreerama Murty, D. Veeraiah, and A. Srinivas Rao, "Digital Signature and Watermark Methods For Image Authentication using Cryptography Analysis," Signal Image Process. An Int. J., vol. 2, no. 2, pp. 170-179, 2011.

[6] L. Machbubah, D. Soetrisno, M. I. Komp, J. Matematika, F. Matematika, and P. Alam, "Watermarking dengan Metode Dekomposisi Nilai Singular pada Citra Digital," J. Sains Dan Seni Pomits, vol. 1, no. 1, pp. 1-6, 2014.

[7] M. Ruswiansari, A. Novianti, T. Informatika, and T. Elektro, "Implementasi Discrete Wavelet Transform ( Dwt ) Dan Singular Value Decomposition ( Svd ) Pada Image Watermarking Implementation Discrete Wavelet Transform ( Dwt ) and Singular Value Decomposition ( Svd ), " pp. 249-259, 2016.

[8] R. Agustina and R. A. Asmara, "Penyisipan Watermark Menggunakan Metode Discrete," pp. 29-34, 2004.

[9] A. R. Hakim, "Universitas Indonesia Analisa Perbandingan Watermarking Image Menggunakan Discrete Wavelet Transform Analisa Perbandingan Watermarking Image Menggunakan Discrete Wavelet Transform," 2012.

https://www.mathworks.com/help/images/ref/imcrop.html (diakses pada tanggal 1 Mei 2017, Pukul 20.00 WIB).

http://www.academia.edu/11385889/Membuat_efek_Blur_invers_crop_dan_Rotate_Pada_Matlab_Praktikum _Pengolahan_Citra_Digital (diakses pada tanggal 1 Mei 2017, Pukul 20.06 WIB). 